Volume 7

Issue 3 May

Article 2

May 1980

\title{
American Health Care: Paradigm Structures and the Parameters of Change
}

Allen W. Imershein

Florida State University

Follow this and additional works at: https://scholarworks.wmich.edu/jssw

Part of the Health Policy Commons, and the Social Work Commons

\section{Recommended Citation}

Imershein, Allen W. (1980) "American Health Care: Paradigm Structures and the Parameters of Change," The Journal of Sociology \& Social Welfare: Vol. 7 : Iss. 3 , Article 2.

Available at: https://scholarworks.wmich.edu/jssw/vol7/iss3/2 


\title{
AMERICAN HEALTH CARE : \\ PARADIGM STRUCTURES AND THE PARAMETERS OF CHANGE
}

\author{
Allen W. Imershein, Special Editor* \\ Department of Sociology \\ Florida State University
}

Recent commentary on the health care scene in the U.S. has moved increasingly toward explanations of why little or no change has occurred despite many declarations of "crisis." From Alford's (1975) elitist analysis in Health Care Politics to Navarro's (1976) marxist analysis in Medicine Under Capitalism, critics in and out of the social sciences have tried to make sense of the array of current problems and the apparent lack of response to or change in them. These analyses are in striking contrast to earlier commentaries (e.g., Schwartz, 1971; Garfield, 1970; Anderson, 1972; Citizens Board, 1972) which, while highly critical of then current health care arrangements, foresaw the potential for change within the system and often made recommendations for potential solutions. If these earlier analyses might be said to have been characterized by an unwarranted optimism regarding the potential for change, the more recent analyses have more than counter-balanced that orientation with an overwhelming skepticism regarding any significant change, short of major societal restructuring. Health care arrangements are seen in these analyses as rooted in the more basic distribution of power and control in the U.S. (from an elitist perspective), or in the fundamental economic structure of the society itself (from a marxist perspective). Thus no significant change should have been, nor can be expected.

At the same time these new criticisms are aired, increasing numbers of attempts at change, specifically in health care, have been noted in the public arena. Government involvement in financing, actual and proposed, the

* My thanks to Julie ōktay for her work as Program Chair of the Division on Health, Health Services, and Health Policy in the Society for the Study of Social Problems in making the initial review and selection of papers for the 1979 meetings from which $\mathrm{I}$ was able to draw for this special issue. 
development of health maintenance organizations (again often under government sponsorship), the establishment of health systems agencies as regulatory organizations, the training of physician extenders and other new allied paraprofessionals, the emergence of family practice as a specialty, the renewed interest in health education, etc., all ostensibly attest to the immense amount of effort being directed toward perceived needs in the health care arena. For an area where, according to our current critics, there is little potential for significant change, there appears to be a lot going on.

The papers in this issue report on some of those "goings on." But they also obviously raise an important question: how does one make sense out of these events especially in light of the above noted commentaries? Each of the papers, to greater or lesser extent, attempts to address that issue, as well as report on one facet or another of the current "redirections" in health care. Likewise, this introduction will attempt, first, to make its own sense of these events, and, second, to place each of the papers in this volume within this sense-making scheme.

\section{Paradigm Structures in American Health Care}

Elsewhere (Imershein, 1977a, 1977b) I have argued the utility of conceptualizing American health care as an organizational paradigm, following Kuhn's (1970) analysis of scientific paradigms. That framework is useful in this context as well, I believe, to examine both the limited potential for significant change and the actual appearance of a wide array of more limited changes. First, American medical practice can best be understood as a paradigm community, with physicians, medical educators, and hospital administrators being the primary community members, and with the general public acting in response to this community. Second, being a paradigm community, its major activities are ordered by virtue of widely shared and taken-for-granted models of practice. Third, these dominant practices are in turn intrinsically linked to a wide range of assumptions about the nature of health, illness, and medicine and about how physicians and health care (or more narrowly, medical care) should be related to the larger society. Finally, given the dominance of this paradigm community within the 
larger society, these practices and assumptions are established as well by custom, by rule of law, by influence over the ongoing political process, and by some control of economic resources relevant to the area of practice.

From this perspective, change in the paradigm occurs in two different ways. First, there are the changes that occur as the result of the "natural" development of the paradigm; e.g., extension of existing patterns of practice to relatively new areas or the development of new modes of practice that are based upon and consistent with existing arrangements (cf. Kuhn, 1970: Ch. 3, for a discussion of scientific paradigm development). Second, major changes, those which fundamentally alter existing practices, only occur through revolution, that is, through a rejection of the paradigm then dominant, and acceptance of a new alternative one. Such change only comes after an extended period of crisis during which numerous unresolvable problems (Kuhn: anomalies) arise. They are both unresolvable by the community of paradigm members and at the same time demand resolution. At this point, alternative models of practice come to be considered which may form the basis for a new paradigm. (For more detail beyond this brief summary, please see Imershein, 1977a, 1977b; Kuhn, 1970.)

Opportunities for significant change within the health arena, then, can be seen from this perspective as severely limited. Change may be limited by the difficulty in modifying the political and economic linkages established between the paradigm community and the larger society (the focus for elitist and marxist analyses noted above). But as well the highly ordered nature of the organization of medical practice as a paradigm community itself intrinsically disallows major change other than under the most extreme of circumstances. Only when problems become so recalcitrant that they appear immune to solution, given present tools and practices, and when the demand for their resolution becomes so overwhelming, only then is major change likely to occur.

What is much more likely to happen when a paradigm community is faced with a variety of initially unresolvable problems is the development of minor modifications to the paradigm that will somehow take care of the problems or make them seem less in need of total resolution. Such changes may be little more extensive than the typical 
incrementalism (or muddling through, cf. Lindblom, 1959) that occurs in the "normal" growth of paradigm practices noted above. However, such changes may be seen as more significant in that: (1) they may be somewhat of a minor break from existing patterns of practice; and (2) they may come to be highlighted as well because of their development as potential responses to problems that have themselves already been in the limelight. Such is the current case with American health care.

Thus we find extensive changes occurring in American health care -- extensive in the sense that they appear in many different segments of health care and that they occupy considerable attention of policy makers and others-without any of those changes, or all of them taken as a whole, necessarily being of great significance.

None of those changes may challenge the fundamental organizational/political arrangements that dominate the current health care scene and have for some time. Nor do they challenge the fundamental assumptions or practices of the dominant health care paradigm.

The "radical critics" may thus be correct in assessing little likelihood of change that would alter the present system. But they would be incorrect to argue that no changes can occur. The most important question is the extent to which the changes that can occur within the present boundaries of the system may make a difference in the health care received by the American public. But to ask this question requires one to ask two further questions: who judges what constitutes "making a difference", and what are the criteria used in making that judgement?

Even with the question stated as above, the further consideration of who judges and by what criteria, still leaves us -- contemporary social scientists and policy makers -- with a range of potential differences, both in viewing the current situation in health care, and in the conclusions we draw. The papers in this volume are no exception, as we will consider below.

\section{Policy Development and the Assessment of Change}

We have presented American health care as constituting an organizational paradigm, have noted that the paradigm is in a state of crisis, and have defined that crisis in 
terms of the appearance of recurrent, demanding, and potentially unresolvable problems. Given this rather large set of assumptions, we can consider the further question of the degree to which changes prompted by the crisis as attempts to resolve the ongoing problems do "make a difference", by what criteria that judgement is made, and who says so. Let us consider the latter -"who says so" -- first.

If we examine the professionals and organizations which constitute at least part of the membership of the organizational paradigm, a number of rather striking characteristics might be noted. First, during a crisis period evaluation comes to be a paramount concern. If a health care organization is challenged as not meeting the needs of its clients; i.e., that it is part of "the problem", then it will either want evidence to refute such challenges, or, alternatively, will accept the allegations as accurate and attempt to implement changes. In either case, the organization will seek data to support its present activities or to evaluate and justify newly instituted changes. (Other obvious scenarios are also possible, but all potentially involve significant use of evaluation.) That is, at a time of crisis and change, evaluation of the current system becomes a paramaount concern, inside as well as outside of the system.

Second, the formulation of policy comes to the fore as a concomitant concern. In "normal times" policymaking is a necessary activity to maintain both order and accountability. In crisis times, effective policy-making, presumably based upon careful evaluation, is seen as the primary means by which problems may be solved and the crisis eventually eliminated. Policy-making itself may in turn become a more focal concern than the activities over which the policy is made.

Third, during a time of crisis, given that the paradigm is at least temporarily unsuccessful in accomplishing the things it is supposed to -- these are the continuing unresolved problems, then the links of the paradigm with the larger society can be seen as potentially threatened; i.e., the legitimacy of the paradigm could be called into question. Whether such questioning of the paradigm's legitimacy is ultimately successful in undermining the links with the larger society (and thereby encouraging the development of a potential alternative paradigm) is 
another question. What is most important is the potential for such undermining. And, where these links are ones of funding (among others), as is the case in health care, then the threat may be seen as very significant indeed. Under such conditions -- which might reasonably be argued the case in current American health care -- the organization will not only have a preeminent concern with evaluation and with policy-making, but may be concerned with these as much for purposes of maintaining legitimacy in the public (or more specifically, governmental) eye, than in using those tools in problem resolution which might eventually eliminate the crisis (cf. Meyer and Rowan, 1977; Imershein et al, 1980; Imershein, 1980). Thus health care organizations may seek evaluations, policy-making, reform commissions, and the like which will provide results consistent with public expectations and particularly those of funding sources. Whether any of these activities have an effect on the continuing problems that are ostensibly their focus may be a secondary concern at best (contrast this with Alford's analysis, 1975: Ch. 2). This does not imply that such organizations are willfully devious (though that may be true on occasion), but that the preeminent requirement of their continuation is both legitimacy and funding, and the problem-solving demanded by the crisis will simply be subsumed under this more immediate demand.

Thus, the consideration of what "makes a difference" may be very important for organizations seeking continued funding and legitimacy in a time of crisis, but what they declare to be important may depend more on the "myths" expected by the public, than anything else (Meyer and Rowan, 1977; Imershein, 1980). Further, the extent to which government reports depend upon the information provided by such organizations, or social science research takes as given the data supplied by the organization itself, then the judgements in those arenas of what changes are significant will be similarly colored.

Turning specifically to the social science arena, and to some of the papers at hand, what "makes a difference" varies considerably depending on the context of the research and on what analytical perspective is brought to bear on the changes under consideration. As noted to be the case with organizations, social scientists concerned with an area in crisis also focus especially on matters of policy-making and evaluation. Much social science work 
is conducted in direct collaboration with or at the behest and funding, directly or indirectly, of the organization(s) being studied. In such cases, the research is likely to be characterized by some of the conditions noted above. And where the government, including government funding agencies, relies extensively on information supplied from the organizations in question, the availability of research funds is likely to be similarly constrained; e.g., to conform to the current expectations so as not to call the legitimacy of the organizations or their efforts at change into question. Since much research requires government funding as an essential resource, any review of research on areas in crisis, as we are attributing to health care, must keep these potential "structural" Iimitations in mind. Marxist analyses which propose to question the legitimacy of the entire health care system, for example, are probably less likely to be funded.

Much "evaluation" research, especially that under sponsorship of the organization being studied, and thus much of the research in the health arena, tends to be programmatic in nature. That is, it takes for granted the assumptions and goals of the organization under study and conducts an evaluation based upon the framework provided within the program oriented perspective of that organization. What "makes a difference" in this case is obviously attuned to the needs of the organization.

Other research which is obviously attuned to issues of evaluation and policy may nevertheless address such concerns from the perspective of a framework outside the organization or with regard to substantive issues not tied to the immediate goals of the organization or service under study. Such is the case with most of the papers in this volume. The majority are concerned in some fashion with one or another of the organizational innovations in the health arena, but address these either from a critical perspective; e.g., marxist, or with regard to a substantive issue; e.g., professional prestige or autonomy.

While the Barr and Steinberg paper ostensibly addresses a programmatic topic, health maintenance organizations, the primary consideration is the relationship of this organizational format, and its requirements, to the more traditional and longstanding requirements of professional autonomy. Likewise Edington's paper on 
Health System Agencies includes, but moves beyond, a simple summary of the development of HSA's to a critical commentary on their limited activity. This commentary is in turn based on an analysis of the conflicts inherent in the way the HSA's have been established and their announced goals promulgated. Lavin's paper considers the use of "non-physicians"; $i . e$. , paraprofessionals of one sort or another, to deliver services, what variation may appear in public acceptance of such personnel, and what might account for that variation. She suggests that where demographic and social psychological variables do not account for differing levels of public acceptance we need to consider the context of service delivery and to reconsider the assumptions typically attributed to the public, especially regarding the level of competence perceived to be required of physicians by the public at large or by specific subgroups.

Three papers, those by Lasker, Bodenheimer, and Imershein and Miller focus on one significant aspect of the current health care arena to critique the development of the system as a whole. Lasker examines the Veterans Administration medical system as providing a potential model (positive or negative) for systematic government involvement in the management of a national health care system. She concludes that: (1) the VA system suffers from the same constraints, economic and political, as do other major departments or programs managed under government auspices; and (2) that a national health system modeled on the VA system would suffer from comparable problems and constraints. Arguing from an explicitly marxist perspective, Bodenheimer examines the development of one particular neighborhood health center as an example of the way in which governmental bureaucratic management serves to suppress rather than support indigenous democratic movements seeking greater responsibility in maintaining the health of the community being served. Imershein and Miller critique the ongoing government thrust that consumer involvement should be a successful countervailing force to make health care institutions more responsive to public needs. Analysis suggests otherwise.

In contrast to the others, the MacDougall paper might be said to be primarily theoretical in nature. The paper presents evidence of changing physician ideologies in the care of the dying, but then considers the 
question of how one explains this change. Considering Parsonian and Marxian arguments as relatively distinct alternatives, MacDougall finds greater support for the Marxist argument; i.e., not that the norms have changed resulting in a change of activities, but that the working conditions and economic arrangements have changed, resulting in a change in the norms.

The papers by Wardwell and by Ford and Ford indirectly trace or document the relatively limited degree of change that has occurred in the health care arena. Wardwell's paper, which is a follow-up to the definitive paper on chiropractic published by the same author some twentyeight years ago, primarily examines the development of chiropractic during that time, but by implication reveals the changes in the health care system over the same period of time, and the changes are very limited indeed. The Ford and Ford paper examines the impact of one of the latest concerns in the health arena, namely health education, to assess relative levels of health knowledge and the relation of health behavior to health knowledge and attitudes. Data analyses suggest that while there may be considerable health knowledge, there appears to be at best a limited relation between knowledge and behavior.

We have, thus, no definitive answer as to what makes a difference. What we do have, however, is a more extensive range of consideration about how one goes about making that decision, either from a research or a policy point of view. The papers in this volume document that fact. They also document the fact that both extremes of previous commentary must be seen as inadequate: one can say neither that "significant" change has occurred and will continue, nor that no change has occurred or could occur. It is not only a problem that our judgements are more difficult, but that we lack consensus over the appropriate way to go about making that judgement and the appropriate criteria to use, again either from a policy or a research perspective. Comparison across the papers in this volume makes this fact apparent also.

In sum, a range of potentially significant changes have been apparent. Either the health care system as a whole, some aspect of it, or the government or other groups in response to it, have initiated what appear to be innovations in response to what they (whichever 
segment that might be) see as problems in the health arena. Lack of sufficient available services has prompted the use of non-physicians to meet the need. Relative lack of coordination and oversight has resulted in the development of Health Systems Agencies as regulatory groups. The lack of alternative service models and the view of health maintenance organizations as promoting an orientation to prevention and cost effectiveness have prompted their sponsorship by the federal government. Neighborhood health centers have been established to better serve and be more responsive to the needs of underserved urban neighborhoods. Consumers are increasingly brought on boards to promote system responsiveness. Models for a national health system are sought, potentially including the VA. Physicians become more open with their patients, including those who are dying. Chiropractic becomes a more acceptable alternative mode of practice. Health education becomes a central concern, at least ideologically, within the system. The list is extensive, but it covers only those topics considered in the present volume, and could be immeasurably extended.

We find a range of assessments from the perspectives presented here. Non-physicians can be used under some circumstances to provide more services. HMO's can be developed without apparently compromising professional autonomy. Health education is a much more widespread concern. Chiropractic is becoming a more viable alternative. But we also find that neighborhood health centers may be only one example of how the government uses programs to limit services to, and exploit the lower classes. Consumers presence on policy boards may be of little worth to increase the responsiveness of the system. The VA system displays all the problems that a national health system would likely face, et cetera. Needless to say, it is difficult to draw any clear conclusions from reviewing the problems and the perspectives.

Why then is it useful to engage in a review such as the one presented in this volume? First, it makes apparent in a concrete way the diversity of problems, programs, and perspectives, the lack of consensus, and the difficulty of drawing conclusions regarding "what makes a difference." Second, it also demonstrates the continuing concern within the field for these issues, and the unwillingness of social science researchers to rest with either of the more extreme positive or negative 
commentaries on the American health care system. But equally important, (1) the diversity of papers in this volume is representative of the larger process of paradigm crisis and reconsideration outlined at the beginning of this introduction. (2) The diversity of perspectives on the significance or viability of the changes under examination is indicative of the differing degrees of commitment to or rejection of the current paradigm. The data do not and cannot "speak for themselves." They are described and understood from a perspective either from within the paradigm, critical of the paradigm, but not totally dismissing it, or from an alternative perspective outside the paradigm. And the continuing process of change, including the possibility of paradigm revolution, is, as the title suggests, inherently a political process. This volume thus becomes both an instance of and a commentary on that process.

\section{REFERENCES}

Alford, Robert R.

1975 Health Care Politics: Ideological and Interest Group Barriers to Reform. Chicago: U. of Chicago Press.

Anderson, Odin $W$.

1972 Health Care: Can There Be Equity? New York: wiley.

Citizens' Board of Inquiry into Health Services for Americans

1972 Heal Yourself. Washington: American Public Health Association.

Garfield, Sidney R.

1970 "The Delivery of Medical Care." Scientific American 222 (April): 15-23.

Imershein, Allen $W$.

1977a "The Epistemological Bases of Social Order: Toward Ethnoparadigm Analysis." Ch. 1 (pp. 1-51) in David Heise (ed.), Sociological Methodology 1977. Washington: Jossey-Bass. 
Imershein, Allen $\mathrm{W}$.

$1977 \mathrm{~b}$ "Organizational Change as a Paradigm Shift." Sociological Quarterly 18 (Winter): 33-43.

1980 "Reform and Legitimacy in Organizational Decision-Making." Paper presented at the annual meeting of the Midwest Sociological Society.

Imershein, Allen W., Michael Frumkin, Richard Chackerian, and Gerald McDonald

1980 "A Critical Research Framework for Assessing Services Integration in Large, Human Resource Agencies." Evaluation and Change (March).

Kuhn, Thomas

1970 The Structure of Scientific Revolutions.

Chicago: U. of Chicago Press.

Meyer, John W. and Brian Rowan

1977 "Institutionalized Organizations: Formal

Structure as Myth and Ceremony." American

Journal of Sociology 83 (No. 2):340-363.

Navarro, Vicente

1976 Medicine Under Capitalism. New York: Prodist.

Schwartz, Harry

1971 "Health Care in America: A Heretical Diagnosis. Saturday Review (August 14): 14-17, 55 . 